\title{
ASPECTO VERBAL NAS CONSTRUÇÕES COM VERBO-SUPORTE
}

\author{
VERBAL ASPECT IN SUPPORT-VERB CONSTRUCTIONS
}

\author{
Larissa PICOLI ${ }^{1}$ \\ Oto Araújo VALE ${ }^{2}$ \\ Eric LAPORTE $^{3}$
}

Resumo: Este artigo tem o objetivo de discutir sobre o aspecto verbal nas Construções com Verbo-Suporte (CVS) e com extensões de verbo-suporte, focalizando a função semântica que os verbos podem ter quando exprimem aspecto. Para isso, analisamos a relação entre frases formadas com vários verbos-suporte e que diferem pelo aspecto. Por exemplo, as frases Zé (ganhou + está com + perdeu a) coragem indicam os aspectos incoativo, durativo e terminativo, respectivamente. Muito se discute sobre as $C V S$, mas o aspecto nessas construções ainda é um assunto de pouco interesse entre os pesquisadores no Brasil. Essa pesquisa está embasada no modelo teórico-metodológico do Léxico-Gramática (LG), desenvolvido por Gross (1975). O LG propõe a descrição e formalização dos itens lexicais em tábuas. Dessa forma, como resultado da descrição formal, apresentamos duas tábuas, que podem ser utilizadas no Processamento de linguagem natural (PLN), por meio de programas de computador.

Palavras-chave: Construções com verbosuporte. Aspecto verbal. Léxico-gramática.

\begin{abstract}
This article aims to discuss verbal aspect in constructions with support-verbs $(C V S)$, focusing on the semantic function of support-verbs as aspect markers. We analyze the relation between sentences formed with various support-verbs and differing in aspect. For example, sentences like Zé (ganhou + está com + perdeua)coragem "Zé(got+has+losthis)courage" indicate respectively inchoative, durative, and terminative aspects. CVS are currently a hot topic, but aspect in these constructions is still a subject of little interest amongst researchers in Brazil. This research is based on the theoreticalmethodological model of the LexiconGrammar (LG), developed by Gross (1975). The LG proposes the description and formalization of lexical items in tables of properties. Thus, the results of our formal description include two tables, which can be used in Natural Language Processing (NLP), through computer programs.
\end{abstract}

Keywords: Support-verb constructions. Verbal aspect. Lexicon-grammar.

\footnotetext{
1 Universidade Federal de São Carlos (UFSCar), São Carlos, São Paulo, Brasil; larissa_picoli@hotmail.com; https://orcid.org/0000-0003-2078-9400

2 Universidade Federal de São Carlos (UFSCar), São Carlos, São Paulo, Brasil; otovale@ufscar.br; https://orcid.org/0000-0002-0091-8079
}

3 Université Gustave Eiffel, Marne-la-Vallée, França; eric.laporte@univ-paris-est.fr; https://orcid.org/0000-0002-0984-0781 
- | Aspecto verbal nas construções com verbo-suporte

\section{Apresentação}

Esta pesquisa investiga o aspecto nas construções com verbo-suporte, doravante CVS, no Português do Brasil. Entendemos CVS como uma construção formada por um verbo-suporte (Vsup) seguido de uma unidade lexical predicativa não verbal, como (1).

(1) Zétem coragem

Usamos o termo consagrado de CVS sem intenção de referir à Gramática das Construções no sentido de Goldberg (1994). Existem várias formas de definir os Vsup, mas, neste artigo, adotamos a definição de Gross $(1981,1998)$ : verbos que se combinam com uma unidade lexical predicativa não verbal formando um predicado semântico completo.

O Vsup de (1) carrega apenas as marcas de tempo, modo, pessoa e número, mas vários Vsup em diversos idiomas possuem variantes que introduzem diferenças aspectuais (LABELLE, 1974; GROSS, M., 1981; LANGER, 2005):

Zé (ganhou+ perdeu a) coragem $^{4}$

Gross (1981, p. 33) introduz o termo de "extensões de verbo-suporte" para esses verbos que são diferentes dos Vsup de base como ter. Nessa perspectiva, a frase (1) com o Vsup ter apresenta o aspecto durativo, mas vemos que o aspecto não é marcado, já que passa a ser pontual se colocamos a frase no pretérito perfeito. As frases de (2) estão no aspecto incoativo, no caso de ganhar, e terminativo, no caso de perder. A única diferença de sentido entre (1) e (2) é de aspecto, enquanto a única diferença de forma é a substituição de ter por ganhar ou perder $a$, o que é um motivo para considerar que "o aspecto se concentra no verbo" (TRAVAGLIA, 2016, p. 261).

O aspecto é uma propriedade das frases que está associada ao tempo. Costa (2016) destaca que aspecto e tempo gramatical são categorias linguísticas temporais, referindose ao tempo físico. Semanticamente essas categorias se diferenciam na medida em que tempo expressa noções de presente, passado, futuro e suas subdivisões e aspecto denota noções como duração, instantaneidade, começo, desenvolvimento, repetição, hábito e fim.

(3) Corriaté a praça

A frase (3) está no tempo passado, já que a ação ocorreu antes do momento da fala, e no aspecto acabado, tendo em vista que a ação já foi concluída, chegou ao fim.

4 O símbolo "+" separa elementos que podem comutar. 
Na literatura, a categoria de aspecto, no estudo do verbo, ganhou destaque nos estudos de Castilho (1967) e Travaglia (2006) e nas gramáticas tradicionais de autores como Bechara (2006), Cunha e Cintra (2017), Cegala (2008). No entanto, esses autores dedicam pouco espaço às extensões aspectuais de Vsup. Por exemplo, Travaglia (2016) aborda esse tema em 3 páginas. Diante disso, ressaltamos a relevância de estudos descritivos sobre aspecto e CVS no Português do Brasil.

Para dissertar sobre o aspecto nas extensões de Vsup neste artigo, optamos pelo modelo do Léxico-Gramática, que veremos na próxima seção, pelo fato de que por meio desse modelo podemos construir recursos linguísticos, no formato de tábuas, que podem ser utilizados no Processamento de Linguagem Natural (PLN), para finalidades como a tradução automática de um texto de língua estrangeira para o português (ou vice-versa), a geração de resumo a partir de um texto fornecido à máquina etc.

\section{O Léxico-Gramática}

O modelo teórico-metodológico do Léxico-Gramática (LG) foi proposto por Gross (1975), a partir de estudos sobre os verbos do francês, com o intuito de descrever o funcionamento sintático dos itens lexicais por meio das noções de distribuição e de transformação entre frases ${ }^{5}$. Esse modelo tem como precursores o distribucionalismo e o transformacionalismo de Harris (1962).

O propósito do distribucionalismo é descobrir como os elementos linguísticos se combinam. Para isso, essa análise explora os paradigmas, observando a seleção e substituição de um item lexical. O transformacionalismo, por sua vez, tem como objetivo descrever as relações entre frases. Dessa forma, propõe, a partir de qualquer frase, aplicar transformações sintáticas e observar a correspondência entre as frases, por exemplo:

$$
\begin{array}{ll}
\text { Zéalugou o carro } & N_{0} \text { alugar } N_{1} \\
\text { O carro foi alugado por Zé } & N_{7} \text { ser alugado Prep } N_{0}
\end{array}
$$

Aplicamos à frase (4) a transformação da passiva, que consiste em utilizar um verbo auxiliar, como ser, e passar o argumento $N_{o}$ para uma posição sintática preposicionada. São exemplos de transformações sintáticas a pronominalização, a apassivação, a nominalização e a formação de uma oração relativa. Interessa, para o LG, tanto as regularidades, quanto as irregularidades da língua, na medida em que esse está baseado no uso efetivo do idioma e investiga a produtividade que as transformações podem ter, incluindo os limites desta produtividade.

5 O LG, em inglês Lexicon-Grammar, é diferente da Lexicogramática, em inglês Lexicogrammar, uma visão da gramática que realça a importância das escolhas lexicais (HALLIDAY, 1985). 
O LG tem como unidade mínima de sentido e de sintaxe a frase elementar. Essa escolha teórica é motivada pela observação de que o significado de uma palavra depende frequentemente dos outros elementos que a acompanham na frase. Com isso, é preferível observar todas as propriedades de um item lexical em frases. Essa precaução metodológica visa também melhorar a confiabilidade da observação semântica. O julgamento semântico aplicado a partes de frases pode variar em função do observador, enquanto o julgamento aplicado a frases completas é mais reprodutível.

Laporte, Smarsaro e Rocha (2012) destacam que o LG investiga o léxico, já que observa as informações sobre as palavras; e a gramática, tendo em vista que analisa as combinações e restrições das palavras. Esse método, portanto, propõe um modelo que atribui a cada item lexical uma gramática, em que cada item lexical pode ter as próprias restrições à aplicação de determinadas operações sintáticas; além disso, no caso de entradas lexicais predicativas, o número de argumentos e a seleção de cada argumento são propriedades gramaticais próprias a cada entrada.

Esse modelo leva a esquadrinhar o léxico, examinando uma por uma as propriedades sintático-semânticas de cada item lexical. O LG propõe apresentar esse tipo de descrição formal em forma de tábuas, também chamadas de tabelas ou matrizes. Nessa formalização dos resultados das análises, nas colunas estão as propriedades formais (estruturais, distribucionais e transformacionais) e nas linhas estão as entradas lexicais. As tábuas são constituídas de sinais binários: marcamos com " + " quando determinado item lexical admite determinada propriedade formal e marcamos com "-" quando ele não aceita a propriedade. Neste artigo, descrevemos diversas variantes aspectuais de CVS em duas tábuas (TÁBUA ASPECTO - 1 e TÁBUA ASPECTO - 2) do LG (ver APÊNDICE).

O conhecimento das transformações permite fazer uma análise transformacional de qualquer frase, decompondo-a em frases elementares (HARRIS, 1962). Cada uma das frases elementares obtidas por esse processo abarca uma parte das informações veiculadas pela frase inicial. Comentando o processo, Sager e Nhàn (2002, p. 88) destacam que "uma análise transformacional de uma frase vai mais longe do que outras análises gramaticais, em um aspecto específico: está mais próxima de uma decomposição informacional da frase". Com efeito, a descrição das propriedades formais no LG requer levar em consideração o conteúdo informacional das construções. Por exemplo, a noção de preenchimento de uma posição argumental pressupõe que a forma que preenche o argumento se combine com o predicado de maneira composicional, ou seja, que a substituição de uma forma por outra altere o sentido da frase de uma forma predizível. Da mesma forma, a noção de operação sintática inclui o fato de que a aplicação de uma operação determinada altere o sentido da frase de uma forma predizível. Nesse sentido, as análises são de natureza sintático-semântica. 
Uma linha de uma tábua do LG é dedicada a uma entrada lexical e descreve construções em que aparece a entrada. Uma dessas construções é escolhida como ponto de referência e as outras são descritas a partir desta, por intermédio de transformações. A construção que serve como ponto de referência é chamada a frase de base da entrada lexical. Sempre se trata de uma frase elementar em que o núcleo do predicado é o item lexical descrito na entrada.

\section{Construções com verbo-suporte}

Existem várias propriedades definidoras de Vsup, aproximadamente equivalentes. Gross (1981, 1998) e Cattell (1984), entre outros, definem Vsup como uma classe de verbos que se liga a uma unidade predicativa não verbal para formar uma "unidade complexa de predicação" (MACHADO VIEIRA, 2014, p. 102). A unidade lexical predicativa funciona como "núcleo predicativo" (ATHAYDE, 2001, p. 10), selecionando argumentos, e pode ser um nome (Npred), um adjetivo ou um sintagma preposicionado cristalizado. Encontraremos exemplos desses três tipos no decorrer deste artigo. A função do Vsup, portanto, é ser suporte flexional para o núcleo predicativo da construção. Esta definição dos Vsup lança mão de uma noção semântica: a de predicado selecionando argumentos, e de uma noção sintática: a de verbo.

Segundo outra definição frequentemente encontrada, os Vsup são caracterizados como verbos com sentido esvaziado (CHISHMAN; ABREU, 2014), uma propriedade que remonta à noção de verbo leve (JESPERSEN, 1942, p. 117), "um verbo insignificativo". Matsumoto (1999), Langer (2005), Storrer (2007) e Kotsyba (2014) adotam em paralelo as definições pelo predicado semântico não verbal e pelo verbo esvaziado de conteúdo semântico.

No quadro teórico do LG, que investiga uma por uma as entradas lexicais, a segunda propriedade definidora pode acarretar obstáculos práticos. Sem possibilidade de medir a "quantidade de sentido", é difícil ponderar se, em determinada construção, como dar um beijo, fazer um acordo, fazer a limpeza, o esvaziamento de sentido é suficiente para classificar o verbo na categoria de $V$ sup. A propriedade depende de um julgamento semântico sobre uma parte de frase e não sobre uma frase inteira. Como já dissemos, o LG evita este procedimento observacional e prefere o critério do predicado semântico não verbal, por ser aplicável por meio de vários índices formais que voltaremos a expor em seguida.

Labelle (1974) é o primeiro a delimitar um amplo conjunto de CVS apresentando determinadas propriedades e a inventariar sistematicamente as entradas lexicais 
- Aspecto verbal nas construções com verbo-suporte

relevantes. Este estudo evidencia a existência de variantes em que o verbo cumpre uma função semântica (LABELLE, 1974):

(6) Paulo tem um acordo com Eva

(7) Paulo faz um acordo com Eva

A substituição de ter porfazerem (6) provoca uma mudança de aspecto: (7) descreve um evento inicial que inaugura a situação de (6). Outros verbos têm uma contribuição ainda mais nitidamente aspectual, como em ganhar coragem e perder a coragem em (2), ou intensiva, como em esbanjar felicidade, ou ainda "modal" (MEYERS; REEVES; MACLEOD, 2004, p. 97), como em carecer de coragem ou fazer uma OPA / tentar uma OPA. Porém, apesar de terem um conteúdo semântico, esses verbos não podem ser analisados como verbos plenos nessas construções. Um verbo pleno seleciona os argumentos, ou seja, determina a distribuição do sujeito e dos complementos, enquanto o sujeito e os complementos de um Vsup não têm uma distribuição característica (RANCHHOD, 1990). Por exemplo, a análise de ganhar e perder como verbos plenos é válida em (8):

(8) Zé (ganhou + perdeu) um relógio

As possibilidades de sujeito e de complemento em (8) são determinadas pelo verbo. Para testar a análise de ganhar e perder como verbos plenos em (2), podemos observar a seleção dos argumentos também. O sujeito humano Zé de (2) não pode ser substituído por qualquer substantivo não humano, o que pode ser verificado pelo fato de que formas como (9) não estão em uso:

(9) *A notícia do incêndio (ganhou + perdeu a) coragem

Essa seleção não é imposta pelos verbos ganhar e perder, e sim pelo Npred coragem, porque, em (10), ganhar e perder aceitam o sujeito não humano que não aceitam em (9):

(10) A notícia do incêndio (ganhou + perdeu a) visibilidade na imprensa

Em (10), o sujeito é selecionado pelo predicado nominal visibilidade. Assim, a análise de ganhar e perder como verbos plenos é inadequada em (2) e (10).

Gross (1981, p. 33) chama "extensão de verbo-suporte" (EVS) esses verbos que, quando substituem os Vsup, cumprem uma função semântica sem que a substituição altere a estrutura argumental da frase e a seleção dos argumentos. Assim, o número de argumentos em (2) e a seleção dos argumentos permanecem os mesmos de (1) .

6 É mais relevante comparar extensões aspectuais a verbos auxiliares do que a verbos plenos, mas o verbo auxiliar é empregado com outro verbo, enquanto a EVS é empregada com um predicado não verbal. Aliás, alguns verbos admitem ambas as sintaxes: começar um estudo / começar a estudar. 
A semelhança entre CVS e EVS tem uma consequência prática: se as entradas lexicais dos nomes predicativos são descritas com base nas CVS em que aparecem esses nomes, a descrição obtida é relevante para as extensões aspectuais também. Assim, no LG, a construção com Vsup de base é sempre escolhida como frase de base do Npred. O vínculo entre CVS e EVS é investigado com inventários sistemáticos de entradas lexicais, no caso do francês, por Vivès (1984) e Danlos (1988), e no caso do português europeu ("substituição de estar por variantes aspectuais"), por Ranchhod (1990, p. 110). Mel'cuk et al. (1995) atribuem o nome de "função lexical sintagmática Oper" à relação entre uma CVS e suas extensões aspectuais. O paralelismo entre $V$ sup de base e extensões de Vsup leva até vários autores a incluir as extensões na categoria dos Vsup (DIESING, 1998; MATSUMOTO, 1999; MEYER; REEVES; MACLEOD, 2004; LANGER, 2005; STORRER, 2007; GARCIA-VEGA; MACHONIS, 2014; KOTSYBA, 2014; MACHADO VIEIRA, 2014; SAMVELIAN; DANLOS; SAGOT, 2014). Quando um tipo de CVS "não admite variantes aspectuais", o fato é digno de ser notado (MOTA; BAPTISTA; BARREIRO, 2018, p. 127). Os manuais de gramática do português que mencionam os Vsup ainda não tratam das EVS (NEVES, 2000), mas não encontramos na literatura publicações que contestassem a relação entre CVS e EVS.

Em prática, a definição das CVS pelo predicado não verbal pode ser aplicada de duas formas: pela intuição semântica, que infelizmente pode carecer de reprodutibilidade, ou por meio de índices formais diretamente observáveis, geralmente mais nítidos. Na perspectiva de uma descrição sistemática de unidades lexicais, a segunda opção é mais satisfatória. Podemos, por exemplo, investigar a seleção dos argumentos, como no caso de (9) e (10): este método consiste em observar combinações sintagmáticas e pode servir para validar ou desvalidar hipóteses, mas não é sempre aplicável. Assim, esse método é completado por outros critérios sintáticos, relativamente técnicos, que são diferentes no caso i) de Vsup elementares ou de base, semanticamente esvaziados, como no exemplo (1), e ii) de extensões de Vsup, com função semântica, como em (2). Os primeiros possuem uma propriedade sintática característica, que vamos resumir a seguir. As extensões de Vsup, por sua vez, podem ser reconhecidas observando as particularidades da transformação entre a CVS de base e a construção com EVS.

O critério formal para reconhecer se um verbo é $V$ sup de base diz respeito a frases complexas em que a suposta CVS é o predicado de uma oração subordinada, como em (11):

\section{(11) A coragem que o Zé teve foi admirável}

Se ter coragem é uma CVS, ela é o predicado da oração relativa que o Zé teve. Uma operação sintática (DALADIER, 1978) aplicada a (11) produz uma variante com o mesmo sentido, mas sem o verbo ter: 
- Aspecto verbal nas construções com verbo-suporte

\section{A coragem do Zéfoi admirável}

O critério consiste em verificar se uma operação sintática com essas características se aplica a algum tipo de frase complexa. Verificamos que o verbo ter é retirado da frase (11) pela operação e que há equivalência semântica entre (11) e (12). Assim, ter é considerado Vsup de base em (11) e, portanto, também na frase (1), que está embutida em (11). Investigações extensas e abrangentes mostraram que é o caso de todos os predicados nominais conhecidos (GROSS, 1981; GIRY-SCHNEIDER, 1987; FOTOPOULOU, 1992; MEYERS; REEVES; MACLEOD, 2004; LANGER, 2005). A retirada do Vsup sem alteração do sentido da frase (11) corrobora a intuição de esvaziamento semântico do verbo, pois essa operação evidencia um contexto em que o verbo pode sumir sem mudança de sentido, mas o critério da retirada é mais confiável do que a intuição de esvaziamento, pois a aplicabilidade de operações sintáticas como a de (11)-(12) pode ser verificada.

Em resumo, o critério que acabamos de descrever restringe $C V S$ a construções com um predicado não verbal que pode também ser empregado sem o Vsup com o mesmo sentido, como nos seguintes grupos nominais: a coragem do Zé, a visibilidade da notícia do incêndio, a OPA da Latam. As operações sintáticas que produzem variantes sem Vsup dependem da categoria gramatical do predicado e do idioma, mas a operação de (11)-(12) funciona com predicados nominais em muitos idiomas.

O leitor pode estranhar que a aplicação de critérios formais, como nas experiências dos exemplos (9)-(10) ou (11)-(12), leve a produzir sequências a fim de verificar se essas estão em uso efetivo na língua. Mas a contradição entre sequência produzida e uso efetivo é só aparente. Uma gramática que visa representar os usos de um idioma deve também, logicamente, caracterizar os limites desses usos. Os corpora existentes não são suficientes para observar esses limites, porque os locutores inventam frases todos os dias. A exploração dos limites necessita também aplicar metodicamente os processos de invenção de frases, especialmente quando se trata de expressões pouco frequentes na escrita ou de processos pouco usados, por que as sequências produzidas têm menos chances de aparecer nos corpora existentes. Quando julgamos que uma sequência produzida está em uso ou não, o julgamento deve ser isento de preconceito e pode ser verificado e desafiado pelo leitor. Assim, o fato de que uma determinada sequência está ou não está em uso não é inventado. Tal fato, por sua vez, pode ser usado para pôr à prova uma análise a fim de verificar se ela é válida.

Gross (1981, 1998), Ranchhod (1983), Cattell (1984) e Machado Vieira (2014) consideram pelo menos algumas frases copulativas como CVS, como em

Ana é corajosa 
Na verdade, em (13), ser corajosa apresenta todas as características de uma CVS, quer intuitivas, quer técnicas, incluindo o critério da retirada do Vsup:

- O que denota a propriedade do sujeito não é a cópula e sim o adjetivo, como pode ser deduzido pela comparação de (13) com Ana é covarde.

- O adjetivo seleciona os argumentos da frase, que neste caso é o sujeito humano Ana.

- O sentido essencial da frase pode ser representado por um predicado semântico, que é idêntico ao de coragem.

- Existe uma operação sintática que produz uma variante sem Vsup a partir de uma frase complexa com uma oração relativa:

(14) Uma mulher que era corajosa lutou pela liberdade

(15) Uma mulher corajosa lutou pela liberdade

Assim, as cópulas podem ser um caso especial de Vsup. Da mesma forma, os outros verbos de ligação podem ser EVS das cópulas ser e estar ${ }^{7}$. Todavia, os manuais de gramática do português ainda não mencionam o comportamento de Vsup dos verbos de ligação (NEVES, 2000).

Os Vsup semanticamente esvaziados, como fazer e ter, conforme aponta Neves (2000), podem, junto com Npred, denotar um sentido global e podem ter, em alguns casos, um verbo pleno correspondente, por exemplo

Zéfez a limpeza do apartamento

(17) Zé limpou o apartamento

O Vsup de base fazer seguido do Npred limpeza em (16) tem o verbo pleno limpar como correspondente, como vemos em (17). É pertinente destacar que não é toda CVS com fazer que vai ter um verbo pleno correspondente, por exemplo:

Zéfez a ata da reunião

*Zé atou a reunião

\footnotetext{
7 As cópulas ser e estar têm uma diferença interessante com muitos outros Vsup conhecidos, como ter ou fazer: o uso de ser e estar como Vsup não se opõe claramente a outro uso dos mesmos verbos com um sentido mais básico. O uso de ser e estar como Vsup é um dos usos mais básicos desses verbos, senão o mais básico. Esse exemplo é um motivo para não considerar como propriedade definidora dos Vsup a oposição entre o uso como Vsup e outro uso mais básico do mesmo verbo. O termo de esvaziamento semântico pode ser interpretado como implicando esta propriedade. Para classificar os padrões sintático-semânticos, parece mais relevante dar prioridade a critérios relativos ao comportamento próprio dos padrões em análise do que à existência de outros usos.
} 
Ranchhod (1990) apresenta várias propriedades sintáticas das CVS, a saber: a) relação entre $N_{o}$ e o Npred, b) formação de frases conversas, c) descida do advérbio, d) retirada do Vsup e formação de grupo nominal, e) restrições nos determinantes e f) substituição do verbo-suporte por variantes aspectuais ou estilísticas.

a) Relação entre $N_{0}$ e o Npred

Como já dissemos, numa CVS quem seleciona os argumentos da frase é o Npred. Gross (1994, p. 237 apud BAPTISTA, 2005) afirma que "Os verbos-suporte são verbos que não apresentam restrições de seleção relativamente ao seu sujeito e complementos. Em vez disso, a relação de seleção estabelece-se entre o sujeito e o complemento". Voltando à frase (16), percebemos que o Npred limpeza não aceita qualquer $N_{0}$ não humano:

${ }^{*}$ O carro fez a limpeza do apartamento

Essa seleção é imposta pelo Npred limpeza e não pelo Vsup fazer, porque o Vsup fazer aceita sujeitos não humanos, por exemplo em

\section{O carro fez um estalo ${ }^{8}$}

b) Formação de frases conversas

G. Gross (1989) traz a transformação de conversão que é uma operação sintática em que o argumento do Npred com função de sujeito na frase de base passa a ser um complemento preposicionado e vice-versa:

Ana deu um tapa em Zé

(23) Zé levou um tapa de Ana

Em (22), a posição de sujeito é preenchida pelo $N_{0}$ humano, $A n a$, e na frase conversa (23), esse argumento torna-se o complemento preposicionado de Ana. O complemento preposicionado de (22) passa pela modificação contrária. A única diferença semântica é que o foco da frase (22) é a Ana e o da frase (23) é o Zé e o sentido da frase não é alterado.

8 Podemos pensar em outra análise, em que fazer em (21) não tem o mesmo sentido de fazer em (16) e corresponde a outro item lexical, que impõe outra seleção do sujeito. Essa análise se baseia numa intuição que atribui uma parte do sentido de (16) a fazer e outra a limpeza, mas não temos como verificar de forma confiável em qual parte de (16) reside cada elemento de sentido, porque o sentido de (16) não é observado senão em (16) inteiro. Alcançamos aqui um limite do julgamento semântico sobre partes de frases. Além disso, se realmente fazer em (16) tem um conteúdo semântico suficiente para selecionar um argumento, é natural esperar que essa seleção suma numa frase em que fazer não estiver presente. Mas isso não acontece:

a) A limpeza do apartamento que foi feita (por Zé + * pelo carro) Levou um dia

b) A limpeza do apartamento (por Zé + * pelo carro) levou um dia

Quando tiramos o Vsup, o argumento carro continua inaceitável, sugerindo que o Npred limpeza seja responsável pela seleção. 
A seleção e os papéis semânticos dos dois argumentos se mantêm: nas duas frases, Ana tem um papel ativo, dinâmico e causal e Zé muda de estado. Baptista (1997) compara a conversão à relação entre uma frase ativa e uma frase passiva, relação em que os papéis semânticos também são conservados.

O critério da retirada do Vsup aplicado a (14) e (15) classifica dar como Vsup de base (o tapa de Ana em Zé) e levar como EVS. Calcia (2016), Calcia e Vale (2019) analisam a conversão no Português Brasileiro em frases com dar, fazer e ter e observam que as EVS que aparecem nas frases conversas, que são também chamadas verbos conversos, são levar, receber, ter e variantes desses verbos. Os pares principais de Vsup com verbos conversos são: dar/receber, dar/levar, fazer/receber e ter/ter. As construções com Vsup dar são as que mais produzem construções conversas, como em:

(24) Zico me deu um conselho

(25) Recebi um conselho de Zico

c) Descida do advérbio

Acontece por meio da substituição do advérbio terminado em -mente pelo adjetivo correspondente modificando o Npred (GIRY-SCHNEIDER, 1987):

(26) Zé assustou bruscamente Ana

(27) Zé deu um susto brusco em Ana

Nesta transformação há equivalência de sentido entre as frases. A modificação que o advérbio promove no predicado verbal não sofre alteração quando ele é nominalizado (BAPTISTA, 2005).

d) Retirada do Vsup e formação de grupo nominal

Essa propriedade é o critério ilustrado pelos exemplos (11) e (12).

e) Restrições nos determinantes

Há CVS que têm restrições quanto aos determinantes possessivos que acompanham o Npred, como

(28) Zéfez um carinho em Ana

(29) Zéfez $\left({ }^{*}\right.$ o meu $+{ }^{*}$ o seu $+{ }^{*}$ o nosso) carinho em Ana

f) Substituição do Vsup por variantes aspectuais ou estilísticas

Alguns Vsup, como já vimos, admitem variantes aspectuais. Vejamos um exemplo: 
- | Aspecto verbal nas construções com verbo-suporte

Zétem raiva de Ana

(31) Zé (ficou + anda + vive + continua) com raiva de Ana

O Vsup ter, na frase de base (30), admite diversas variantes que alteram o significado de forma predizível. As variantes em (31) apresentam as mesmas propriedades de ganhar e perder que notamos em (2) e, portanto, podem ser analisadas como EVS. A diferença principal é que ocorrem com a preposição com. O estudo de Santos (2015) sobre os predicados nominais com Vsup ter menciona duas outras variantes de ter: estar com e sofrer de, que não contribuem nitidamente para o aspecto da frase, mas também são construídas com preposições. Há diversas pesquisas recentes sobre CVS que seguem o modelo teórico-metodológico do LG e mencionam diversas variantes aspectuais, dentre as quais se destacam Rassi (2015), que descreve e classifica o verbo dar, Barros (2014), que apresenta a descrição e classificação dos predicados nominais com Vsup fazer, Chacoto (2005) que disserta sobre o verbo fazer em construções nominais predicativas, Malacoski (2017), que descreve o Vsup ter e nomes humanos de relação, entre outros.

\section{A função semântica dos Vsup}

O estudo de Gross (1998) sobre a função semântica dos Vsup é um dos resultados de um empreendimento coletivo e metódico de descrição das CVS e EVS em francês e em outros idiomas, que Gross tinha orientado continuamente desde 1970 e que deu origem à publicação de teses, artigos e livros. Esse artigo, portanto, leva em consideração as lições aprendidas na investigação de milhares de entradas lexicais.

No início, Gross (1998) se vale da noção de transformação sintática de nominalização. Esse processo consiste em, a partir de uma frase formada com um verbo distribucional, transformar esse verbo em nome. Gross cita, por exemplo, o equivalente francês de:

(32) Zégritou

(33) Zédeu um grito

O verbo distribucional gritarem (32) é nominalizado em (33), grito, e o verbo da frase transformada é o Vsup dar. Gritar é considerado um verbo pleno ou verbo distribucional, tendo em vista que é ele quem seleciona os argumentos da frase, e em (32) há apenas um argumento: o sujeito. E dar é um Vsup, pois não é ele que seleciona o sujeito e sim o nome predicativo (Npred) grito. Harris (1981) ressalta que no processo de transformação de uma frase em outra se mantém o sentido. Isso quer dizer que há correspondência semântica entre (32) e (33). 
Gross destaca que o Vsup, por exemplo, o equivalente francês de dar em (33), é semanticamente esvaziado assim como os verbos fazer e ter nas frases:

(34) Zé dividiu as tarefas

(35) Zéfez a divisão das tarefas

(36) Suas palavras importam

(37) Suas palavras têm importância

Em (35) e (37) a função dos Vsup é de reestruturar sintaticamente a frase, mas sem modificar o sentido. As relações de sentido entre os verbos e o sujeito e entre os verbos e os complementos se mantêm entre a frase verbal e a transformada. Em (35), por exemplo, o complemento as tarefas manteve a mesma relação de sentido com divisão que tinha em (34) com dividir.

Gross (1998) investiga as relações semânticas entre CVS de base semanticamente esvaziados, como (38), e construções com EVS, como (39), no intuito de estudar a função semântica dos Vsup, por exemplo, em (1) e (2), repetidos aqui por conveniência:

(38) Zétem coragem

(39) Zé (ganha + perde a) coragem

Para cada extensão de Vsup em (39), comparamos semanticamente a construção de base com a construção com a extensão de Vsup e verificamos se as construções são equivalentes semanticamente ou se há diferença semântica. Podemos perceber que entre (38) e (39) existe uma diferença semântica de aspecto. O aspecto de (38) é durativo. Tomando como referência (38), em (39) as frases exprimem os aspectos incoativo (ganhar) e terminativo (perder). Passando as frases para o pretérito perfeito, (38) se torna pontual, mas (39) conserva os aspectos incoativo e terminativo. Assim, ganhar e perder podem ser considerados como marcas de aspecto em (39).

Para discutir a função semântica dos Vsup, Gross (1998) analisa o efeito semântico de várias operações sintáticas que introduzem EVS em frases formadas com Vsup de base em francês. Existem situações paralelas em português do Brasil. Mencionamos a seguir três dessas operações sintáticas:

a) Relações entre frases com Vsup e frases causativas e agentivas

$$
\text { Zétem medo de aviões }
$$

Essa notícia deu medo de aviões em Zé

Vemos que a frase de base (40) é formada com Vsup ter, que é semanticamente esvaziado, enquanto em (41) há o verbo causativo, dar, e um argumento adicional, essa 
- | Aspecto verbal nas construções com verbo-suporte

notícia, que denota a causa da situação expressada por (40). Gross (1998) classifica o equivalente francês de dar em (41) como EVS.

b) Relações entre frases com Vsup e frases com Vsup intensivos

Frases com Vsup semanticamente esvaziados podem ser comparadas com frases mais expressivas:

(42) Zé tem (coragem + entusiasmo + alegria + desejo)

(43) Zé esbanja (coragem + entusiasmo + alegria + desejo)

O sentido de (43) não corresponde ao sentido concreto de esbanjar (Rochinha esbanja a herança em orgias) e sim ao sentido de (42), a única diferença semântica com (42) sendo a maior intensidade e expressividade de (43). Os argumentos não diferem. Os argumentos permanecem selecionados pelo Npred. Por exemplo, (42) e (43) não admitem o sujeito não humano prédio, enquanto esse sujeito se torna possível com outros Npred:

(44) O prédio tem estilo

(45) O prédio esbanja estilo

Isso caracteriza esbanjar em (43) e (45) como uma EVS com valor semântico intensivo.

c) Associação entre o aspecto e o Vsup

Deixamos por último o tópico sobre o aspecto, pois ele é o centro deste artigo. Tomamos como ponto de referência uma frase com Vsup de base:

(46) Zéfez a montagem do filme

Substituindo o Vsup, a frase passa a exprimir aspecto:

(47) Zé (iniciou + terminou) a montagem do filme

O verbo iniciar exprime o início da ação e terminar denota o fim.

Gross (1998) classifica o aspecto presente nas CVS, por comparação com uma frase de referência, em quatro grupos: incoativo, durativo, terminativo e de repetição ou de frequência. Primeiramente apresentamos as frases de base e na sequência tratamos dos quatro grupos.

Na frase de base de uma expressão com Vsup, o verbo é semanticamente esvaziado:

(48) Zétem inveja de Ana

(49) Zéfezfofoca de Ana 
Ficar sem internet é um pé no saco

Esta intuição de um verbo semanticamente esvaziado pode ser corroborada por operações sintáticas de retirada do verbo:

A inveja que você tem de Ana é insuportável = Sua inveja de Ana é insuportável

Repeti a fofoca que vocêfez de Ana = Repeti sua fofoca de Ana

Acho que esse programa é um pé no saco = Acho esse programa um pé no saco

Além dos verbos ser, ter e fazer, Gross (1998) cita os equivalentes franceses dos Vsup estar e proceder $a$ :

(51) Zé está azul de fome

(52) Zé procedeu à leitura da ata

Cabe salientar que há frases que admitem mais de um Vsup semanticamente esvaziado, como acontece em

Zé(tem + está com) esperança

Em (53), a frase com estar pode ser percebida como menos durativa do que a frase com ter, mas a diferença semântica não é saliente.

Para simplificar a organização do LG, as transformações sintáticas são representadas nas tábuas no Léxico-gramática tomando como ponto de referência uma construção única, que é a frase de base. Em se tratando de aspecto, todas as transformações que aplicamos partem, então, da construção de base. Portanto, o efeito semântico de uma operação sintática, e em especial o efeito aspectual, não pode ser descrito, em todo rigor, como um aspecto absoluto e sim como uma diferença relativa ao aspecto da construção de base. Por exemplo, as frases de (47) são incoativa e terminativa relativamente a (46), no sentido em que elas denotam o início e o fim da ação denotada por (46). Da mesma forma, o aspecto de (6) pode ser descrito como durativo de forma absoluta, mas resultativo relativamente a (7); simetricamente, o aspecto de (7) é pontual de forma absoluta, mas incoativo relativamente a (6).

O aspecto incoativo exprime o início de uma ação ou de um estado. Castilho (1967, p. 41) denota o aspecto de "início" pelos termos de "inceptivo" (p. 19), "incoativo" (p. 67) e "ingressivo" (p. 41). As diferenças semânticas entre essas categorias aparecem nítidas em alguns exemplos, mas não em todos e não encontramos na literatura sobre aspecto critérios formais para corroborar a intuição semântica em exemplos duvidosos. Tais critérios são necessários num empreendimento de descrição sistemática de entradas 
- | Aspecto verbal nas construções com verbo-suporte

lexicais. Assim, não tentamos distinguir várias categorias de "início", e usamos o termo de incoativo, que é generalizado hoje. Gross (1988) destaca como incoativos os equivalentes franceses dos verbos se tornar, ir e cair, por exemplo

(54) Zé (é + se tornou) um mala sem alça

(55) O carro (está em + foi para o + saiu para o) conserto

(56) Essa palavra (está + cai) em desuso

Podemos citar como verbos incoativos também ficar, virar, ganhar, como vemos em:

(57) Zé (é + ficou + virou) um mala sem alça

(58) Zé(tem + ganhou) coragem

Os verbos entrar, juntar, tomar, iniciar podem denotar aspecto incoativo, por exemplo:

(59) Zé (está + entrou) numa enrascada

(60) Zé (tem + juntou + tomou) coragem

(61) Zé (fez + iniciou) um discurso

Alguns verbos auxiliares podem denotar aspecto incoativo, por exemplo, dar:

(62) Ana deu de cantar no coral da igreja

Rassi (2015) mostra que o verbo auxiliar dar de pode ser parafraseado pelo auxiliar começar $a$, que também exprime aspecto incoativo:

(63) Ana começou a cantar no coral da igreja

Tendo em vista que neste artigo analisamos o aspecto verbal em construções com Vsup Npred, não nos interessam aqui as construções com verbo auxiliar.

O aspecto durativo denota que a ação ou o estado é contínuo e duradouro. Gross (1998) traz como exemplos os equivalentes franceses dos Vsup permanecer, conservar e manter, como nas frases:

(64) Zé (é + permanece) uma manteiga derretida

(65) Zé (tem + mantém) a cabeça no lugar

(66) Zé (tem + mantém + conserva + permanece com) o plano

Ademais destacamos também as variantes continuar, viver, andar e prosseguir:

(67) A situação (está + continua + vive + anda + prosseguia) ruça

(68) Zé (está + continua + vive + anda) mal das pernas 
Algumas variantes expressam matizes aspectuais sutis: por exemplo, viver em (67) parece introduzir um aspecto intermediário entre durativo e de frequência.

É pertinente destacar o comportamento do Vsup estar:

(69) Zé (está + continua + vive) azul de fome

O verbo estar em (69) pode ser escolhido como Vsup de base, porque satisfaz o critério da retirada sem mudança semântica:

Zé saiu já estando azul de fome = Zé saiu já azul de fome

Já em (70), esse mesmo verbo estar comuta com ser:

(70) Ana (é+está) um violão

A frase (70) é durativa, mas com uma diferença aspectual dependendo do verbo. A frase com o verbo estar denota uma situação ocasional ou episódica, enquanto a frase com ser descreve uma situação estável. Os dois verbos podem ser retirados sem mudança semântica:

(71) Eu acho que Ana é um violão

(73) Eu acho que Ana está um violão
$=(72)$ Eu acho Ana um violão

= (72) Eu acho Ana um violão

As construções (71) e (73) são aspectualmente diferentes, mas (72) pode ser equivalente a qualquer uma dos dois, dependendo do contexto. Portanto, ser e estar podem ser escolhidos como Vsup de base. Escolhendo ser que ocorre com essa expressão mais comum e mais naturalmente, a substituição de ser por estar passa a contribuir para um matiz aspectual que pode ser descrito, em comparação com a frase de base, como mais ocasional ou episódico.

O aspecto terminativo é aquele que exprime a finalização ou o encerramento de uma ação ou estado. Os equivalentes franceses de sair, terminar e perder são verbos que podem denotar aspecto terminativo, de acordo com Gross (1998), por exemplo

Zé (está em + saiu de) uma enrascada

(75) Zé (tem + perdeu a) paciência

Com extensões de Vsup terminativas, o determinante do Npred costuma ter uma distribuição diferente do que com o Vsup de base.

Também podemos citar o verbo concluir como terminativo:

$$
\text { Zé (faz + concluiu) a leitura dos poemas }
$$


- | Aspecto verbal nas construções com verbo-suporte

Por fim, verbos como repetir e reiterar introduzem uma noção aspectual de repetição ou frequência, por exemplo:

(77) Zé (repete + reitera) a atividade

(78) O vendedor (repete + reitera) a contagem

Já mencionamos viver que contribui para um aspecto intermediário entre iterativo e de frequência.

Gross (1998) ressalta que há verbos que denotam repetição ou frequência e exigem complementos necessariamente no plural, como acontece com multiplicar e acumular:

Zé (multiplicou + acumulou) os (erros + prejuízos + benefícios)

De maneira organizacional, apresentamos os quatro grupos da classificação aspectual separadamente. No entanto, vale destacar que uma CVS pode simultaneamente admitir mais de uma extensão de Vsup com diferentes aspectos, por exemplo:

(80) Ficar sem internet (é + está + tornou + virou + ficou + continua + anda) um pé no saco

(81) Zé (faz + iniciou + mantém + continua com + repete + reitera + acumula) as atividades

(82) Zé (fez + iniciou + prosseguiu + concluiu + repetiu) a leitura

Organizamos várias extensões de Vsup que denotam aspecto em duas tábuas (TÁBUA ASPECTO - 1 e TÁBUA ASPECTO - 2) (ver APÊNDICE) no formalismo do LG. Na TÁBUA ASPECTO - 1, há as entradas que têm Vsup de base ser ou estar, já na TÁBUA ASPECTO - 2 são as que têm Vsup de base ter,fazer, ser de, estar Prep e proceder $a$. Nas tábuas, apresentamos uma amostra de diversas expressões com verbo-suporte, e codificamos várias extensões aspectuais de Vsup. Verificamos que todas as entradas são CVS, aplicando critérios de validação da análise como Vsup de base. Essas propriedades definidoras de Vsup não são marcadas, pois as tábuas só contêm entradas em que essas propriedades são positivas. As propriedades marcadas são aquelas que dependem das entradas: entre outras, o valor do Vsup e das EVS. Seguindo o formalismo proposto pelo LG, marcamos com sinal "+" (positivo) quando a construção admite determinada propriedade, como distribuição do sujeito e variantes aspectuais, e com sinal "-" (negativo) quando não admite a propriedade.

Esse modelo de codificação binário (+) e (-) é utilizado para tratamento automático de linguagem. Dessa forma, essas tábuas representam um recurso linguístico que pode ser incluído em bases de dados de dicionário eletrônico para o Processamento Automático de Linguagem Natural. 


\section{Considerações finais}

Este artigo descreve uma das funções semânticas principais das extensões de verbos-suporte, a contribuição ao aspecto verbal. Dessa forma, analisamos a relação entre a frase de base e frases formadas com extensões de Vsup que carregam aspecto.

Valendo-nos dos estudos de Gross (1998), classificamos as extensões aspectuais de Vsup em quatro grupos: incoativo, durativo, terminativo e de repetição ou de frequência. Descrevemos essa classificação em tábuas, no formalismo do LG, levando em conta sete Vsup de base e vinte e cinco ${ }^{9}$ extensões de Vsup, subdivididas nos quatro grupos da classificação aspectual.

Levamos em conta várias extensões aspectuais de Vsup ainda não investigadas no português do Brasil. Verificamos que o essencial das análises publicadas anteriormente na literatura sobre extensões aspectuais de Vsup em outros idiomas pode ser adaptado ao português do Brasil e que o raciocínio obtido permanece válido. Em especial, a relação entre construção com Vsup de base e construção com extensão de Vsup pode ser definida por meio de critérios sintático-semânticos aplicáveis em prática.

Ressaltamos que a discussão e descrição propostas aqui são introdutórias para os estudos sobre aspecto na perspectiva do LG. Desse modo, se torna relevante classificar um quantitativo maior de construções com Vsup e consequentemente descrever mais extensões de Vsup. Destacamos assim possibilidades de trabalhos futuros que ampliem o número de construções analisadas, explorando também outros Vsup.

\section{Agradecimentos}

Agradecemos aos pareceristas anônimos da revista pelas observações e pelos questionamentos sobre uma versão anterior deste artigo.

\section{Referências}

ATHAYDE, M. F. Construções com verbo-suporte (Funktionsverbgefüge) do português e do alemão. Coimbra: Universidade de Coimbra, 2001.

BAPTISTA, J. Sermão, tareia e facada: uma classificação das expressões conversas darlevar. Seminários de Linguística, Faro, v. 1, p. 5-38, 1997.

9 Há alguns verbos que ocorrem com e sem preposição, dependendo de qual verbo são variantes aspectuais. Nesses casos, contabilizamos apenas uma vez o verbo, mesmo que ele apareça em duas colunas. 
- | Aspecto verbal nas construções com verbo-suporte

BAPTISTA, J. Sintaxe dos predicados nominais com ser de. Lisboa: Fundação Calouste Gulbenkian, 2005.

BARROS, C. D. Descrição e classificação de predicados nominais com o verbo-suporte fazer no português do Brasil. 2014. Tese (Doutorado em Linguística) - Centro de Educação e Ciências Humanas, Universidade Federal de São Carlos, São Carlos, 2014.

BECHARA, E. Moderna gramática portuguesa. Rio de Janeiro: Lucerna, 2006.

CALCIA, N. P. Descrição e classificação das construções conversas do português do Brasil. 2016. Dissertação (Mestrado em Linguística) - Centro de Educação e Ciências Humanas, Universidade Federal de São Carlos, São Carlos, 2016.

CALCIA, N. P.; VALE, O. A. Construções conversas do português do Brasil: descrição e classificação iniciais. Linguamática, v. 10, n. 2, p. 13-20, 2019.

CASTILHO, A. T. de. Introdução ao estudo do aspecto verbal na língua portuguesa. Alfa, Marília, v. 12, p. 11-135, 1967.

CATTELL, R. Composite Predicates in English. Sydney: Academic Press, 1984.

CEGALLA, D. P. Novíssima gramática da Língua Portuguesa. 48. ed. São Paulo: Companhia Editora Nacional, 2008.

CHACOTO, L. O verbo fazer em construções nominais predicativas. 2005. Tese (Doutorado em Linguística) - Universidade do Algarve, Faro, 2005.

CHISHMAN, R. L. de O.; ABREU, D. T. B. de. Construções com verbos-suporte: propriedades gramaticais e discursivas. Linha D’Água, v. 27, n. 1, p. 153-168, 2014.

COSTA, S. B. B. O aspecto em português. 3. ed. São Paulo: Contexto, 2016.

CUNHA, C.; CINTRA, L. Nova gramática do português contemporâneo. 7. ed. Rio de Janeiro: Lexikon, 2017.

DALADIER, A. Quelques problèmes d'analyse d'un type de nominalisation et de certains groupes nominaux français. 1978. Tese (Doutorado em Linguística) - Université Paris 7, Paris, 1978. 
DANLOS, L. Les phrases à verbe support être Prép. Langages, v. 90, p. 23-37, 1988. DOI: 10.3406/lgge.1988.1989

DIESING, M. Light verbs and the syntax of aspect in Yiddish. The Journal of Comparative Germanic Linguistics, v. 1, p. 119-156, 1998.

FOTOPOULOU, A. Dictionnaires électroniques des phrases figées. Traitement d'un cas particulier: phrases figées/phrases à Vsup. In: KIEFER, F.; KISS, G.; PAJZS, J. COMPLEX. Papers in Computational Lexicography. Budapest: Hungarian Academy of Sciences, 1992. p. 147-161.

GARCIA-VEGA, M.; MACHONIS, P. The Support Verb take. In: KAKOYANNI-DOA, F. Penser le Lexique-Grammaire. Perspectives actuelles. Paris: Honoré Champion, 2014. p. 111-123.

GIRY-SCHNEIDER, J. Les nominalisations en français. L'opérateur faire dans le lexique. Genève: Droz, 1978.

GIRY-SCHNEIDER, J. Les prédicats nominaux en français. Les phrases simples à verbe support. Genève: Droz, 1987.

GOLDBERG, A. Constructions: a Construction Grammar Approach to Argument Structure. Chicago: Chicago University Press, 1994.

GROSS, G. Les constructions converses du français. Genève: Droz, 1989.

GROSS, M. Méthodes en syntaxe. Paris: Hermann, 1975.

GROSS, M. Les bases empiriques de la notion de prédicat sémantique. Langages, v. 63, p. 7-52, 1981. DOI: 10.3406/lgge.1981.1875

GROSS, M. Constructing Lexicon-Grammars. In: ATKINS, B.; ZAMPOLLI, A. Computational Approaches to the Lexicon. Oxford: Oxford University Press, 1994. p. 213-263.

GROSS, M. La fonction sémantique des verbes supports. Travaux de Linguistique, v. 37, n. 1, p. 25-46, 1998. 
- | Aspecto verbal nas construções com verbo-suporte

HALLIDAY, M. A. K. Systemic Background. In: BENSON, J. D.; GREAVES, W. S. Systemic Perspectives on Discourse. v. 1. Norwood: Ablex, 1985. p. 1-15.

HARRIS, Z. S. String Analysis of Sentence Structure. The Hague: Mouton, 1962.

HARRIS, Z. S. The Elementary Transformations. In: HARRIS, Z. S. Papers on Syntax. Dordrecht: D. Reidel Publishing Company, 1981. p. 211-235.

JESPERSEN, O. A Modern English Grammar on Historical Principles. Part VI. Morphology. London: George Allen and Unwin Ltd., 1942.

KOTSYBA, N. How light are aspectual meanings? In: ROBERING, K. Events, Arguments, and Aspects. Amsterdam/Philadelphia: John Benjamins, 2014. p. 261-300.

LABELLE, J. Étude de constructions avec opérateur avoir (nominalisations et extensions). 1974. Tese (Doutorado em Linguística) - Université Paris 7, Paris, 1974.

LANGER, S. A formal specification of support verb constructions. In: LANGER, S.; SCHNORBUSCH, D. Semantik im Lexikon. Tübingen: Gunter Narr, 2005. p. 179-202.

LAPORTE, E.; SMARSARO, A.; ROCHA, L. H. P da. Um recurso linguístico para o processamento automático de linguagem natural: descrição do verbo passar. In: CARMELINO, A. C. et al. Questões linguísticas: diferentes abordagens. Vitória: UFES, 2012. p. 141-156.

MACHADO VIEIRA, M. dos S. Idiomaticidade em construções com verbo suporte do português. Soletras, v. 28, p. 99-125. 2014. DOI: 10.12957/soletras.2014.14200

MALACOSKI, L. A. S. Descrição sintático-semântica de construções com o verbosuporte ter e nomes humanos de relação para o Processamento Automático de Linguagem Natural. 2017. Dissertação (Mestrado em Linguística) - Centro de Ciências Humanas e Naturais, Universidade Federal do Espírito Santo, Vitória, 2017.

MATSUMOTO, M. Composite Predicates in Middle English. In: BRINTON, L. J.; AKIMOTO, M. Collocational and Idiomatic Aspects of Composite Predicates in the History of English. Amsterdam/Philadelphia: John Benjamins, 1999. p. 59-94. 
MEL'CUK, I.; CLAS, A.; POLGUÈRE, A. Introduction à la lexicologie explicative et combinatoire. Louvain-la-Neuve: Duculot, 1995.

MEYERS, A.; REEVES, R.; MACLEOD, C. NP-external arguments. A Study of argument sharing in English. In: ACL Workshop on Multiword Expressions. Integrating

Processing. Proceedings... Association for Computational Linguistics, 2004. p. 96-103.

MOTA, C.; BAPTISTA, J.; BARREIRO, A. The Lexicon-Grammar of Predicate Nouns with ser de in Port4NooJ. In: 12th International Conference Nooj 2018. Berlin: Springer, 2019. p. 124-137.

NEVES, M. H. M. Gramática de usos do português. São Paulo: UNESP, 2000.

RANCHHOD, E. M. On the support verbs ser and estar in Portuguese. Lingvisticae Investigationes, v. 7, n. 2, p. 317-353, 1983. DOI: 10.1075/li.7.2.07ran

RANCHHOD, E. M. Sintaxe dos predicados nominais com estar. Lisboa: Instituto Nacional de Investigação Científica, 1990.

RASSI, A. P. Descrição, classificação e processamento automático das construções com o verbo dar em português Brasileiro. 2015. Tese (Doutorado em Linguística) - Centro de Educação e Ciências Humanas, Universidade Federal de São Carlos, São Carlos, 2015.

SAGER, N.; NHÀN, N. T. The computability of strings, transformations, and sublanguage. In: NEVIN, B. E.; JOHNSON, S. B. The legacy of Zellig Harris. v. 2. Amsterdam/ Philadelphia: John Benjamins, 2002. p. 79-120.

SAMVELIAN, P.; DANLOS, L.; SAGOT, B. On the predictability of light verbs. In: KAKOYANNI-DOA, F. Penser le Lexique-Grammaire. Perspectives actuelles. Paris: Honoré Champion, 2014. p. 209-221.

SANTOS, M. C. A. dos. Descrição e classificação dos predicados nominais com o verbo-suporte ter em Português do Brasil. 2015. Tese (Doutorado em Linguística) Centro de Educação e Ciências Humanas, Universidade Federal de São Carlos, São Carlos, 2015. 
- | Aspecto verbal nas construções com verbo-suporte

STORRER, A. Corpus-based investigations on German support verb constructions. In: FELLBAUM, Ch. Collocations and Idioms: Linguistic, Lexicographic, and

Computational Aspects. London: Continuum, 2007. p. 164-188.

TRAVAGLIA, L. C. O aspecto verbal no português: a categoria e sua expressão. Uberlândia: EDUFU, 2006.

VIVÈS, R. L'Aspect dans les constructions nominales prédicatives: avoir, prendre, verbe support et extension aspectuelle. Lingvisticae Investigationes, v. 8, n. 1, p. 161-185, 1984. DOI: 10.1075/li.8.1.11viv

COMO CITAR ESTE ARTIGO: PICOLI, Larissa; VALE, Oto Araújo; LAPORTE, Eric. Aspecto verbal nas construções com verbo-suporte. Revista do GEL, v. 18, n. 1, p. 204-229, 2021. Disponível em: https://revistadogel.gel.org.br/

Submetido em: 07/10/2020 | Aceito em: 23/01/2021. 
APÊNDICE

\begin{tabular}{|c|c|c|c|c|c|c|c|c|c|c|c|c|c|c|c|c|c|}
\hline \multicolumn{18}{|c|}{ TÁBUA ASPECTO-1 } \\
\hline \multirow[t]{2}{*}{ Npred } & \multicolumn{4}{|c|}{ NO } & \multicolumn{2}{|c|}{ base } & \multicolumn{4}{|c|}{ Incoativo } & \multicolumn{6}{|c|}{ Durativo } & \multirow[b]{2}{*}{$\begin{array}{l}\frac{\pi}{x} \\
\frac{0}{3} \\
\frac{3}{0} \\
0\end{array}$} \\
\hline & 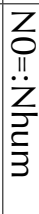 & 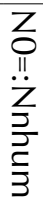 & Z & Z & $\stackrel{\mathscr{D}}{n}$ & 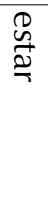 & $\begin{array}{l}\frac{+}{0} \\
\frac{1}{3} \\
\frac{1}{2} \\
0\end{array}$ & $\Rightarrow$ & & & $\frac{\bar{D}}{\bar{D}}$ & 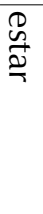 & 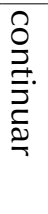 & 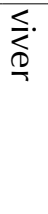 & & 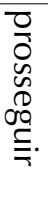 & \\
\hline azul de fome & + & - & - & - & - & + & + & + & - & + & + & 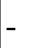 & + & + & + & - & Zé está azul de fome \\
\hline mala sem alça & + & - & - & - & + & - & + & + & - & + & + & + & + & - & - & - & Zé é um mala sem alça \\
\hline bem da cabeça & + & - & - & - & - & + & - & + & - & - & - & - & - & - & + & - & Zé não está bem da cabeça \\
\hline cortar o coração & - & + & - & - & + & - & - & - & - & - & - & - & - & - & - & - & $\begin{array}{l}\text { Essa história é de cortar o } \\
\text { coração }\end{array}$ \\
\hline violão & + & - & - & - & + & - & + & - & - & + & - & + & + & - & - & - & Ana é um violão \\
\hline manteiga derretida & + & - & - & - & + & - & + & + & - & + & + & {$[-$} & + & - & + & - & Zé é manteiga derretida \\
\hline mal das pernas & + & + & - & - & - & + & - & + & - & - & + & - & + & + & + & - & Zé está mal das pernas \\
\hline ruça & - & + & - & - & - & + & + & + & - & - & + & {$[-$} & + & + & + & + & A situação está ruça \\
\hline cama & + & - & - & - & - & + & - & + & + & - & + & - & + & + & + & + & Zé está de cama \\
\hline pé no saco & + & + & + & + & + & - & + & + & - & + & - & + & + & - & + & - & $\begin{array}{l}\text { Ficar sem internet é um pé } \\
\text { no saco }\end{array}$ \\
\hline
\end{tabular}


- | Aspecto verbal nas construções com verbo-suporte

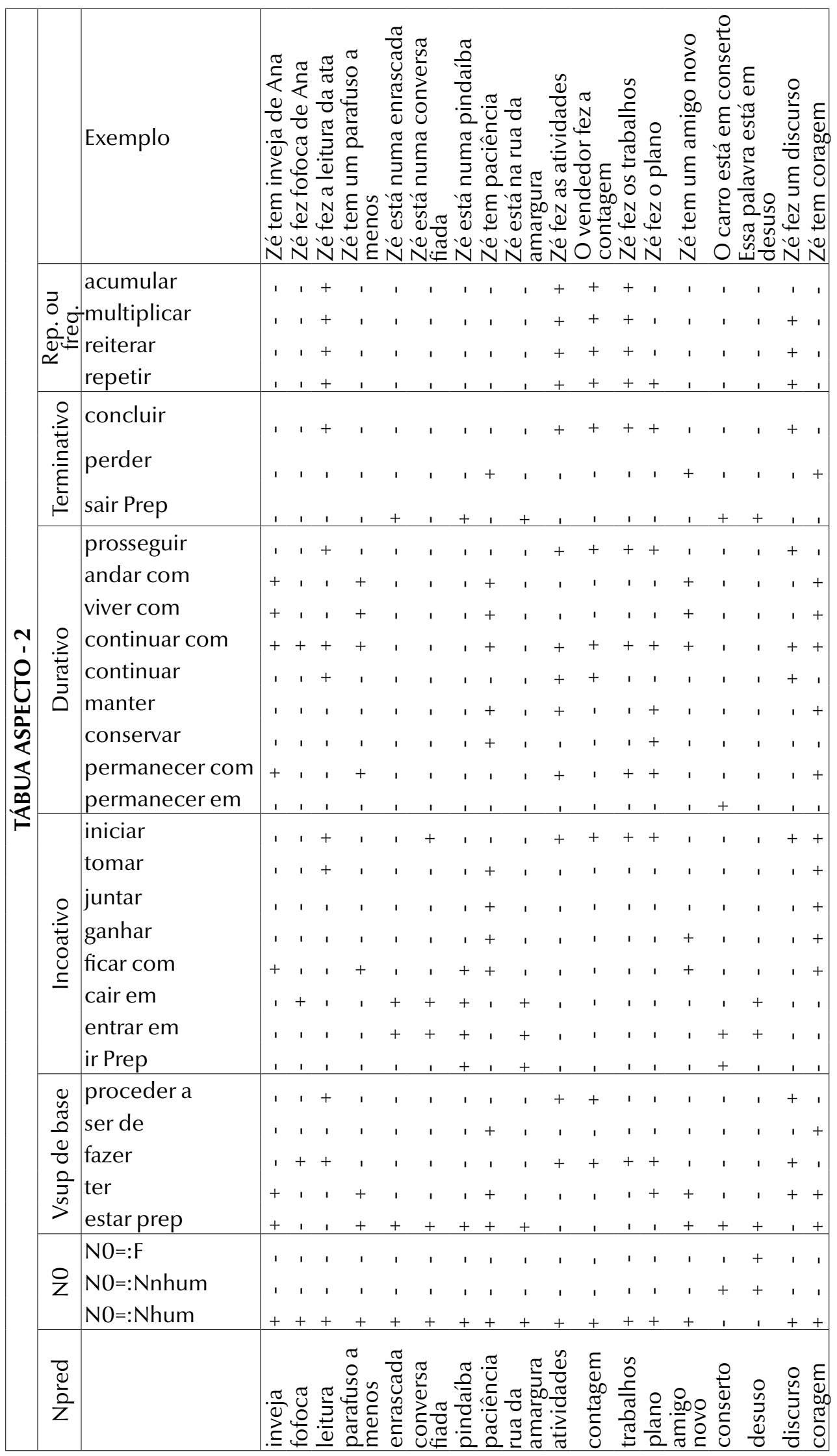

